\title{
Penggunaan Biografi Sultan Syarif Abdurrahman Alkadrie Sebagai Sumber Pembelajaran Sejarah
}

Haris Firmansyah*, Agus Sastrawan Noor, Ika Rahmatika Chalimi

Universitas Tanjungpura

*Corresponding author`s e-mail: harisfirmansyah@untan.ac.id

\begin{abstract}
History learning must present the surrounding environment as a source of learning to students so that learning is more meaningful because it is still often found that many students do not know their own local history, in this case the teacher can make the biography of an influential figure in the city of Pontianak, namely Sultan Syarif Abdurrahman as a source of history learning. This study aims to describe the biography of Sultan Syarif Abdurrahman and to find out how to use the biography in history learning. This research is a basic research using descriptive-qualitative form. Data collection techniques used include: direct observation, indepth interviews and reviewing documents and archives. This research was conducted in the odd semester of the 2020-2021 academic year in three schools namely SMA Negeri 5, SMA Negeri 6 and SMA Negeri 9 Pontianak with interactive analysis techniques. The results of this study are (1) A long journey has been written by Sultan Syarif Abdurrahman. Starting from the establishment of the city of Pontianak to the developments that occurred in the kingdom of Pontianak during his reign. The Sultan who was very religious, wise and firm was also depicted from the stories in the history books of the founding of the city of Pontianak. (2) Utilizing the biography of Sultan Syarif Abdurrahman as a learning resource to provide variety in history learning to students. Utilization of the biography of Sultan Syarif is carried out by conducting historical tours to three locations related to Sultan Syarif Abdurrahman, namely the Jami' Mosque, Kadriah Palace and the Sultan Eating Complex in Batu Layang. The implication of this research is that the development of local history materials can be used by history teachers in almost every history material contained in the curriculum.
\end{abstract}

Keywords: resources; study; history; sultan; Pontianak

Abstrak: Pembelajaran sejarah harus menghadirkan lingkungan sekitar sebagai sumber belajar kepada peserta didiknya agar pembelajaran lebih bermakna karena masih sering dijumpai peserta didik banyak belum mengenal sejarah lokalnya sendiri, dalam hal ini guru dapat menjadikan biografi tokoh yang berpengaruh di kota Pontianak yakni Sultan Syarif Abdurrahman sebagai sumber pembelajaran sejarahnya. Penelitian ini bertujuan untuk mendeskripsikan biografi Sultan Syarif Abdurrahman serta mengatahui bagimana penggunaan biografi tersebutdalam pembelajaran sejarah. Penelitian ini merupakan penelitian dasar dengan menggunakan bentuk deskriptif-kualitatif. Teknik pengupulan data yang digunakan antara lain: Observasi langsung, Wawancara mendalam serta Mengkaji dokumen dan arsip. Penelitian ini dilaksanakan pada semester ganjil tahun ajaran 2020-2021 di tiga sekolah yakni SMA Negeri 5, SMA Negeri 6 dan SMA Negeri 9 Pontianak dengan teknik analisis interaktif. Adapun hasil penelitian ini adalah (1) Perjalanan panjang telah digoreskan oleh Sultan Syarif Abdurrahman. Mulai dari pendirian kota Pontianak hingga perkembangan yang terjadi di kerajaan Pontianak pada masa pemerintahannya. Sultan yang sangat religius, bijaksana dan tegas pun tergambarkan dari cerita-cerita dalam buku-buku sejarah berdirinya kota Pontianak. (2) Memanfaatkan biografi Sultan Syarif Abdurrahman menjadi sumber belajar untuk memberikan variasi dalam pembelajaran sejarah kepada peserta didik. Dalam Pemanfaatan biografi Sultan Syarif ini dilaksankan dengan melakukan wisata sejarah ke tiga lokasi yang berkaitan dengan Sultan Syarif Abdurrahman yakni Masjid Jami', Istana Kadriah dan Komplek Pemakan Sultan Di Batu Layang. Implikasi penelitian ini bahwa pengembangan materi sejarah lokal dapat digunakan oleh guru sejarah hampir pada setiap materi sejarah yang terdapat di kurikulum.

Kata kunci: sumber; belajar; sejarah; sultan; Pontianak 


\section{Pendahuluan}

Pembelajaran Sejarah seharusnya merupakan sebuah pemahaman mengenai masa lalu untuk dijadikan pembelajaran masa sekarang karena sejarah merupakan dialog dari masa lalu dengan masa kini bahkan kuat kaitanya dengan masa yang akan dating (Hasbullah \& Supriadi, 2012). Pembelajaran sejarah sangat erat kaitannya dengan masyarakat sebagai objeknya. Sudah semestinya pembelajaran sejarah dapat mendekatkan peserta didik dengan masyarakat. Sehingga peserta didik dapat berinteraksi secara langsung dengan masyarakat dan mengenal serta menghargai nilai-nilai yang terkandung di dalam lingkungan masyarakat tempat peserta didik itu tinggal (Amboro, 2015). Persoalan yang selalu dihadapi dalam pembelajaran sejarah di sekolah adalah terdapatnya citra negatif yang melekat di ruang lingkup peserta didik yang sering menganggap pembelajaran sejarah adalah pembelajaran yang selalu mencatat dan menghafal sehingga peserta didik tidak tertarik dan bosan dalam proses pembelajarannya (Sayono, 2013). Semua itu erat kaitannya dengan guru yang bersifat sentral dalam pembelajaran sejarah.

Guru menjadi ujung tombak dalam proses pembelajaran sejarah di sekolah. Sehingga jika guru sejarah lemah dalam memberikan metode dan model pembelajaran sejarah tanpa adanya inovasi maka pesan yang tersampaikan dalam pembelajaran sejarah tidak dengan baik dipahami. Inovasi pembelajaran sejarah dapat dilakukan guru dengan memanfaatkan berbagai media pembelajaran metode pembelajaran serta termasuk dalam melakukan pengembangan materi ajar yang berkaitan dengan sejarah lokal. Inovasi perlu dilakukan dalam pembelajaran dengan tujuan meningkatkan minta dan motivasi belajar peserta didik (Pramayogi et al., 2019). Inovasi pembelajaran sejarah tentu juga harus beranjak dari semngat dan motivasi guru sejarahnya terlebih dahulu. Sirnayatin (2017)dalam penelitian mengatakan bahwa guru harus memiliki wawasan yang luas serta motivasi yang tinggi dalam proses pembelajaran sejarah sehingga tidak saja inovasi pembelajaran sejarah tercipta namun pembelajaran akan mencapai tujuannya. Tercapainya tujuan dan efektifias pembelajaran ini sangat penting untuk dicapai dalam proses pelaksanaan pembelajaran (Sari, 2017).

Pengembangan materi sejarah dengan memasukan materi sejarah lokal merupakan bagian dari inovasi pembelajaran sejarah. Sehingga pembelajaran sejarah tidak saja terfokus dengan buku teks atau buku paket mata pelajaran sejarah. Menurut Sulistyo (2019) walaupun kurikulum nasional sudah menetapkan standar dalam materi yang harus dicapai dalam pembelajaran sejarah, guru memiliki hak untuk mengembangkan materi ajarnya dengan memanfaatkan sejarah lokal. Hal ini dikarenakan peserta didik tidak dapat dijauhkan 
dengan identitas komunitas terdekatnya terlepas dari pemahaman sejarah nasional yang didapatkan peserta didik (Purnaman, 2016). Agar peserta didik cenderung lebih mengenal sejarah nasional yang lingkupnya kebanyakan di pulau Jawa dari pada sejarah yang ada di lingkungan peserta didik itu tinggal. Salah satu upaya yang bisa dilakukan dalam mengatasi permasalahan-permasalahan yang ada yaitu memberikan materi-materi sejarah local yang sangat erat kaitannya dengan lingkungan sekitar peserta didik tinggal. Sehingga peserta didik tidak hanya dapat mengetahui sejarah nasional saja tetapi dapat juga lebih mengenal identitas komunitasnya yaitu lingkungan sekitar peserta didik tinggal. Dengan memanfaatkan biografi tokoh sebagai sumber pembelajaran sejarah.

Pengembangan materi sejarah lokal dalam pembelajaran sejarah secara tidak langsung akan menciptakan transfer nilai-nilai kearifan lokal kepada peserta didik (Romadi \& Kurniawan, 2017). Salah satu materi sejarah lokal yang dapat dikembangkan oleh guru sejarah adalah biografi tokoh-tokoh lokal yang memiliki peran penting dalam perkembangan daerah dan masyarakatnya, contohnya adalah biografi tokoh pendiri kota Pontianak yaitu Sultan Syarif Abdurrahman ALkadrie. Mempelajari biografi memiliki manfaat bagi pesarta didik. Biografi yang ditulis dengan baik dapat membangkitkan inspirasi terhadap para pembaca dan menjadikannya fungsi terpenting di dalam pendidikan. Di dalam biografi pula pembaca dapat memiliki imajinasi untuk mendalami perihal kehidupan pribadi seseorang yang dimulai dari latar belakang, sosio kultural dan proses pendidikannya. Sehingga menimbulkan rasa empati pembaca (Kartodirdjo, 1993).

Banyak peserta didik di SMA kota Pontianak masih belum mengetahui tentang Biografi Sultan Syarif Abdurrahman ALkadrie. Walaupun situs-situs peninggalannya sangat dekat dan berkaitan dengan lingkungan sekitar peserta didik tinggal. Mereka belum mengetahui bagaimana sumbangsih Sultan Syarif Abdurrahman dalam mendirikan kota Pontianak yang saat ini dijadikan ibukota provinsi Kalimantan Barat. Semestinya peserta didik dapat diarahkan untuk memanfaatkan literatur yang ada untuk membaca kisah tentang Sultan Syarif Abdurrahman. Beberapa litaratur hasil penelitian terkait Sultan Syarif Abdurrahman yakni salah satunya penelitian yang ditulis oleh Hasanuddin (2000) yang di dalamnya terdapat cerita tentang Sultan Syarif Abdurrahman. Kemudian penelitian yang dilakukan oleh Sirrullah (2019) yang mendeskripsikan tentang sejarah Sejarah Kesultanan Kadriah Pontianak 1778-2017 M di dalam hasil penelitianya juga ada becerita atau berkisah tentang Sultan pertama Pontianak tersebut. Masih banyak lagi buku yang tertuliskan mengenai sejarah berdirinya kota Pontianak dan tak terlepas oleh tokoh utamanya yaitu Sultan Syarif Abdurrahman. Tetapi banyak peserta didik yang tidak mengenal secara spesifik mengenai ketokohan Sultan Syarif Abdurrahman, perjalanan dan perjuangannya untuk 
mendirikan kota Pontianak, adanya peninggalan berupa Majid Jami' dan Istana Kadariah merupakan bukti kuat peran beliau dalam perkembangan dan Syiar Islam di Kota Pontianak. Oleh karena itu dibutuhkan adanya sejarah local dalam memberikan pengetahuan peserta didik dalam menjadikannya motivasi, teladan, hingga untuk dapat lebih peka terhadap yang terjadi di lingkungan sekitar peserta didik. Penelitian ini bertujuan untuk mendeskripsikan biografi singkat Sultan syarif Abdurrahaman ALkadrie serta bagaimana biografi Sultan Syarif Abdurrahman tersebut untuk digunakan sebagai sumber pembelajaran sejarah.

\section{Metode}

Peneliti dalam penelitian ini menggunakan bentuk Penelitian dasar (basic research) karena peneliti menerapkan beberapa tahapan sehingga menjadi dasar dalam penelitian ini tiga tahapan tersebut yaitu : 1) Tahap Orientasi, yang merupakan tahap awal untuk menemukan hal-hal yang menjadi focus penelitian seperti hal yang penting, menonjol, dan berguna untuk diteliti secara mendalam. Sehingga diharapkan dengan tahap awal ini menjadikan peneliti tidak canggung dalam menjalin hubungan dengan orang-orang yang terlibat di dalam penelitian; 2) Tahap Eksplorasi, yang merupakan lebih mendalami focus penelitian dengan melakukan observasi sehingga dapat mengumpulkan data yang lebih terarah dan spesifik; dan 3) Tahap Member Check, yaitu tahap pemeriksaan terhadap semua kebenaran data yang sudah didapatkan dan disusun dalam laporan. Sehingga penelitian mendapat data yang akurat dan valid. Dan hasil wawancara terhadap setiap informan disusun dan dianalisis dengan menggunakan pendekatan empiris (Sutopo, 2006).

Penelitian ini dilaksanakan pada semester ganjil tahun ajaran 2020-2021 di tiga sekolah yakni SMA Negeri 5 Pontianak, SMA Negeri 6 Pontianak dan SMA Negeri 9 Pontianak. Adapun sumber data yang digunakan dalam penelitian ini adalah : (1) Informan yaitu seseorang yang memberikan informasi tentang focus permasalahan yang ada di penelitian ini. Pada penelitian ini informan awal terdiri dari guru sejarah SMA se-Kota Pontianak yang pernah menggunakan biografi Sultan Syarif Abdurrahman Alkadrie sebagai Sumber Pembelajaran Sejarah. (2) Tempat yang memiliki keterkaitan dengan Sultan Syarif Abdurrahman yakni Masjid jami' Pontianak, Istana Kesultanan Pontianak, dan Makam Batulayang. (3) Dokumen berupa dokumen surat-surat, arsip, buku-buku (referensi) yang berkaitan dengan sejarah biogrfai Sultan Syarif Abdurahman, foto maupun rekaman didapat dari sumber baik Informan maupun yang berasal dari tempat penelitian serta dokumentasi yang dimiliki oleh person maupun lembaga tertentu. Teknik yang digunakan dalam pengumpulan data dalam penelitian ini adalah sebagai berikut : 1) Observasi langsung, peneliti melakukan pengamatan dalam pelaksanaan pembelajaran sejarah yang 
memanfaatkan biografi sultan Syarif Abdurrahman sebagai sumber belajarnya2) Wawancara mendalam (indepth interview), wawancara peneliti lakukan kepada informan yang terdiri dari guru sejarah SMA Negeri 5 Pontianak, SMA Negeri 6 Pontianak dan SMA Negeri 9 Pontianak beserat beberapa peserta didiknya. Untuk itu diperlukan pedoman wawancara (interview guide) agar wawancara lebih mendalam dan terarah; dan (3) Mengkaji dokumen dan arsip (content analysis) tentang Biografi Sultan Syarif Abdurrahman sebagai sumber pembelajaran sejarah. Sumber data ini merupakan data terpenting dalam menemukan data yang beragam sesuai kebutuhan dan tujuan penelitian.

Penelitian ini bersifat deskriptif-kualitatif dengan teknik analisis interaktif (Miles, M.B. \& Huberman, 1984). Teknik analisis interaktif terdiri dari tiga komponen analisis meliputi reduksi data, sajian data dan penarikan kesimpulan atau verifikasi. Penggunaan penelitian kualitatif di atas dimaksudkan untuk dapat mementingkan proses pengumpulan data yang beragam dan disusun secara khusus untuk dikelompokkan melalui proses pengumpulan data secara teliti dan saling berkaitan (bottom up grounded theory) (Sutopo, 2006).

\section{Hasil Dan Pembahasan}

\section{A. Biografi Sultan Syarif Abdurrahman Alkadrie}

Syarif Abdurahman Alqadrie lahir di Matan, pada hari Senin, 15 Rabiul Awal 1154 H. Anak dari pernikahan antara Al-Habib Husin dengan Putri Nyai Tua. Al Habib Husain merupakan mufti atau pemangku adat Kerajaan Matan yang menikahi seorang dayang di Kerajaan Matan, Putri Nyai Tua. Syarif Abdurrahman memiliki tiga saudara yang tertua bernama Syarifah Khadijah, dan kedua adiknya bernama Syarifah Mariyam dan Syarif Alwie atau dikenal dengan Tuan Bujang. Pada 8 Muharram $1160 \mathrm{H}$, Habib Husain beserta keluarganya termasuk Syarif Abdurrahman bertolak ke Kerajaan Mempawah. Saat itu Syarif Abdurrahman berusia masih sangat belia yakni 6 tahun (Poestaka, 1926). Tercatat sudah selama 17 tahun berada di Kerajaan Matan. Dan semua itu atas undangan dan permintaan Raja Mempawah Daeng Manambon untuk bisa Habib Husain dan keluarganya tinggal di Mempawah. Kemudian mereka membangun pemukiman di Galah Herang di kawasan kerajaan Mempawah. Setelah dua tahun Kerajaan Mempawah, Syarif Abdurrahman yang ketika itu sudah berumur 18 tahun dinikahkan dengan Utin Candramidi, putri Opu Daeng Manambo. Setelah itu Syarif Abdurrahman dianugerahi gelar Pangeran Syarif Abdurrahman Al-Qadrie (Firmanto, 2012). Masa muda Syarif Abdurrahman penuh dengan petualangan. Setelah 20 tahun lamanya di Mempawah, Syarif Abdurrahman belayar ke Tambelan, Riau, Palembang kemudian ke Banjarmasin (Poestaka, 1926). Di Banjarmasin ia berdagang 
rempah-rempah, lada, kain-kain sutra, lenen, dan hasil perkebunan lainnya. Bahkan berperang, dan berhasil mengalahkan kapal Prancis di Pasir (Kalimantan Timur), mengalahkan jung-jung Cina serta petualangan lainnya (Andi, 2010). Dengan armada, peralatan dan barang modal semakin bertambah dari hari ke hari sehingga ia berhasil mendapatkan apa yang diinginkannya. Di Banjarmasin Syarif Abdurrahman diberi gelar Syarif Abdurrahman Nur Alam oleh Sultan Saad setelah diangkat menantu dengan dinikahi dengan putrinya yang bernama Syarifah Anom atau Ratu Syahranom. Pernikahan itu dianggap sebagai pernikahan politik untuk memperkuat aliasi tiga kerajaan yang ada di Kalimantan: Mempawah, Matan, dan Banjar (Firmanto, 2012). Ketika Syarif Abdurrahman ikut mengatur kerajaan, ia dimusuhi oleh para pembesar kerajaan Banjar, sehingga ia memilih untuk kembali ke kerajaan Mempawah pada 11 Rabiul Akhir 1185 H (Hasanuddin, 2014).

Syarif Abdurrahman diperintahkan oleh Panembahan Mempawah untuk mengusir bajak laut di muara Sungai Kapuas yang sudah menyerang kapal-kapal VOC dan menimbulkan kerugian. Disaat itu juga Syarif Abdurrahman kurang disenangi dikalangan pembesar Kerajaan Mempawah. Pada tanggal 17 Oktober 1771/ 8 Rajab 1185 H, Syarif Abdurrahman bersama pengikutnya dari orang-orang Bugis meninggalkan Mempawah dengan 14/15 kapal kecil. Dengan rute Sungai Kapuas ke Sungai Peniti dan sebaliknya. Pengalaman Syarif Abdurrahman dalam berniaga memberikan arti dalam menentukan wilayah yang strategis bagi jalur pelayaran niaga, karena letaknya berada pada pertemuan sungai besar yakni Sungai Kapuas dan Sungai Landak (Hasanuddin, 2014). Kawasan yang dibuka oleh Sultan Syarif Abdurrahman menurut cerita tempat itu belum pernah diinjakkan kaki oleh manusia, tetapi terkenal sebagai tempat tinggal hantu-hantu. Sehingga untuk mengusir itu ditembakilah tempat itu oleh perahu-perahu yang sudah diperintahkan Syarif Abdurrahman untuk mengelilinginya (Veth, 2012).

Legenda pengusiran hantu inilah kemudian lekat cerita-cerita yang beredar di masyarakat bahwa kata Pontianak berasal dari Kuntilanak (hantu yang diusir oleh Sultan). Namun menurut keterangan lain sebenarnya yang diusir itu bukanlah hantu, melainkan sarang bajak laut (perompak) sebagaimana Syarif Abdurrahman diminta untuk mengusir bajak laut. Ditemukanlah tempat yang menjadi sarang bajak laut itu (antara Batu Layang dan Nipah Kuning sekarang). Syarif Abdurrahman menembakkan meriam ke tempat persembunyian bajak laut tersebut dan akhirnya mereka meninggalkan kawasan itu (Hasanuddin, 2014). Setelah keberhasilan Syarif Abdurrahman mengusir para bajak laut itu kemudian beliau beserta rombongan yang dibawanya membuka pemukiman di lokasi yang 
masih hutan belantara. Posisi strategis dalam mendirikan pusat pemerintahan dan perdagangan. Dan pertama-tama yang dibangun ialah perumahan pemukiman dan surau (langgar) untuk tempat ibadah (Pemerintah Provinsi Kalimantan Barat, n.d.). Pengikut lainnya mulai membangun bangunan pemukiman serta kampung di tepi sungai (Veth, 2012). Pemilihan tempat yang strategis membawa keberhasilan untuk banyak pedagang datang mengunjungi Bugis, Melayu, Cina, juga dari Sanggau, Sukadana, Mempawah dan Sambas (Kartodirjo, 2014). Pada 8 Syahban 1192 H diadakan upacara peresmian Kerajaan Pontianak dengan mengangkat Syarif Abdurrahman Nur Alam yang memiliki gelar Maulana Sultan Syarif Abdurrahman dinobatkan sebagai Sultan di Kerajaan Pontianak. Upacara itu dihadiri oleh para Sultan dan Panembahan dari Kalimantan Barat. Penobatan itu dilakukan oleh Yang Dipertuan Haji Raja Muda dari Riau atas nama seluruh rakyat (Hasanuddin, 2014).

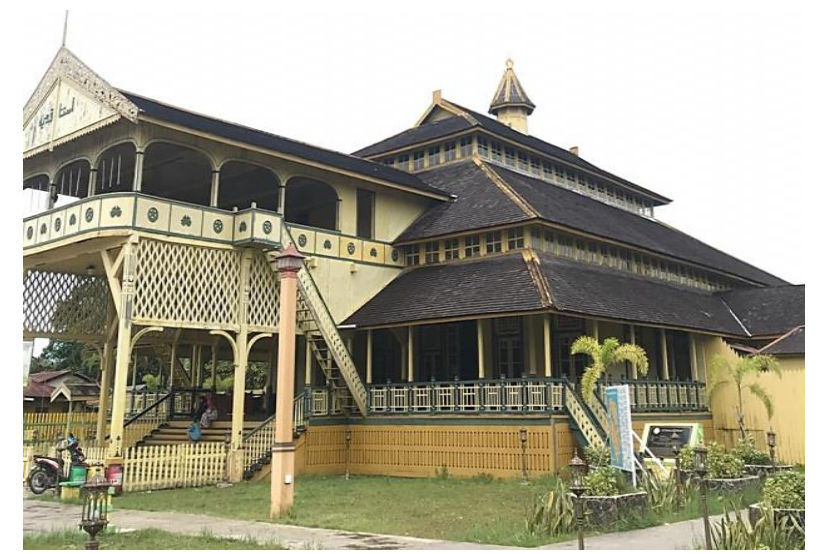

\section{Gambar 1. Kesultanan Qadriyah yang didirikan Sultan Syarif Abdurrahman (Dokumentasi Penulis, 2020)}

Bentuk istana dari gambar 1 yang dapat kita lihat di atas bukanlah bangunan istana bentuk awal yang dibangun oleh Sultan Syarif Abdurrahman. Istana tersebut telah mengalami banyak perubahan dalam proses sejarah yang panjang. Bangunan istana Kadriah yang tampak sekarang ini merupakan bentuk bangunan terakhir yang direnovasi oleh Sultan Muhammad Alkadrie pada tahun 1923 (Asma Dz, 2013). Letak geografis kesultanan Pontianak memiliki keuntungan dalam segi geopolitik dan geostrategis. Sehingga pendiri kesultanan ini -Sultan Syarif Abdurrahman--- disebut sebagai ahli Maritim yang memungkinkan serangan militer ke jantung kesultanan ini dapat dimentahkan (Firmanto, 2012). Dan Pontianak menjadi tempat dimana bertumpuknya barang-barang dari hulu dan luar negeri yang membuat raja-raja di hulu menjadi iri hati dan marah. Mereka mengancam akan menghancurkan kesultanan Pontianak yang baru berdiri itu. Tetapi Panembahan Adi Jaya yang merupakan ipar dari Syarif Abdurrahman menuliskan surat yang mendesak semua raja-raja di hulu untuk membatalkan niat mereka itu (Willer, 2015). Kemajuan dalam hal 
perdagangan di Pontianak, membuat Syarif Abdurrahman melakukan ekspansi untuk menguasai Sanggau. Pada tanggal 26 Maret 1778, dengan adanya bantuan VOC Pontianak berhasil menguasai Sanggau. Dan setelah itu semakin kuat hubungannya dengan diangkatnya Willem Adrian Palm sebagai perwakilan VOC di Pontianak. VOC pun mengajukan kontrak pertama kali kepada Sultan Syarif Abdurrahman tanggal 5 Juli 1779. Kontrak tersebut ditujukan untuk memberikan ikatan yang sangat mengikat untuk setiap kerajaan sehingga ketika pengangkatan sultan dan para pembesar kerajaan lainnya harus sepengetahuan mereka (Hasanuddin, 2014).

Adanya intervensi yang dilakukan oleh VOC dalam urusan internal kerajaan membawa kerajaan Pontianak terlibat dalam urusan pertikaian politik dan ekonomi antar kerajaan. Terdapat beberapa konflik yang melibatkan Pontianak diantaranya dengan Mempawah dan Sukadana. Konflik dengan Mempawah terjadi dikarenakan Mempawah menjadi factor penghalang kemajuan perdagangan di Pontianak. Sedangkan konflik dengan Sukadana dikarenakan mengalirnya komoditas perdagangan dari hulu sungai Kapuas ke Sukadana sehingga Pontianak mengalami penurunan dalam pemasukan bea dan cukai (Hasanuddin, 2016). Pada tanggal 1 Muharram 1223 H, Sultan Syarif Abdurrahman bin Husin Al Kadri wafat dalam usia 66 tahun. Beliau dimakamkan di makam Batu Layang. Sebelum meninggal, ia memiliki keinginan agar anaknya Syarif Kasim tetap memerintah di Mempawah. Dan sedangkan Syarif Osman gantikan ia di Pontianak (Willer, 2015).

Gambar 2 merupakan komplek pemakaman kerbat Istana Kadriah. Disanalah Sultan Syarif Abdurahman dimakamkan. Mulanya di areal ini juga menjadi areal pemakaman Panglima Laskar siak yang membantu Sultan Syarif Abdurahman ketika perang melawan Sanggau. Terdapat sekitar tiga ribu makam di kompleks pemakaman ini. Sekitar 500 di antaranya terdapat dalam bangunan utama makam. Makam Sultan Syarif Abdurahman sendiri berada pada posisi depan tengah dari bangunan utama ini. Terbuat dari kayu belian bertingkat dua, dengan ukiran berselur dan ditutupi kelambu bewarna kuning terang. Disampingnya terdapat makam istri serta permaisuri yakni Puteri Utin Chandramidi (Asma Dz, 2013). 


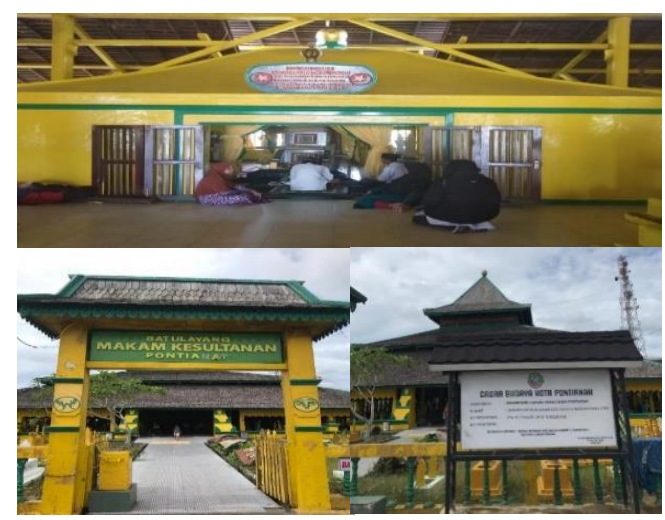

\section{Gambar 2. Makam Sultan Syarif Abdurrahman Alkadrie di komplek Makam Kesultanan Pontianak di Batu Layang \\ (Dokumentasi Penulis, 2020)}

\section{B. Biografi Sultan Syarif Abdurrahman Sebagai Sumber Pembelajaran Sejarah}

Pada perkembang kurikulum pendidikan kita saat ini telah membuka ruang untuk guru mengembangkan motode mengajarnya serta materi yang akan diajarkanya berdasarkan kebutuhan peserta didik. Begitu juga pada pembelajaran sejarah, guru dapat melakukan pengembangan baik dari segi motode, media dan materi yang akan diajarkan kepada peserta didiknya. Di Kota Pontianak guru sudah melakukan hal tersebut terutama dalam pengembangan materi sejarah yang dikaitkan dengan materi sejarah lokal. Pengambangan materi sejarah lokal ini dipandang oleh guru penting untuk dilakukan guna mengenalkan peserta didik terhadap lingkungannya sendiri dan menjadikan pembelajaran sejarah lebih bermakna.

Untuk mencapai tujuan pembelajaran sejarah guru dituntut untuk dapat mengaktifkan kesadaran sejarah peserta didik. Dengan memanfaatkan realitas lingkungan guru dapat membawa peserta didik belajar sejarah secara langsung, kerena keterikatan peserta didik sebagai bagian manusia sosial yang hidup dilingkungannya sendiri tentu sangat efektif untuk mengaktifkan kesadaran sejarahnya. Lokalitas memiliki daya tariknya sendiri untuk membuat peserta didik menjadi aktif dalam proses pembelajaran (Firmansyah, 2019). Hal-hal yang menjadi permasalahan tersebut seharusnya menjadi evaluasi guru untuk dapat menerapkan metode dan startegi pembelajaran lebih inovatif dan variatif yang mampu menimbulkan minat peserta didik untuk belajar sejarah. Konsep dari pembelajaran dengan menggunakan kearifan lokal merupakan ciri khas dari tujuan pembelajaran di Indonesia yang mengedepankan budaya dari masing-masing suku yang terdapat di Indonesia (Hidayat et al., 2020). Guru sejarah ketika mengajar berusaha untuk menghubungkan dan mengambangkan materi ajarnya pada kehidupan di lingkungan sekitar peserta didik. Hal ini 
dapat bermanfaat dalam menumbukan rasa keperdulian peserta didik dalam kehidupan bermasyarakat dan cenderung tidak mengabaikan. Dan dengan pengembangan pembelajaran sejarah itu dapat mengembangkan pengetahuan peserta didik mengenai kearifan local yang ada di sekitarnya. Pengembangan sumber belajar tidak hanya pada Silabus yang telah ditetapkan oleh pemerintah saja. Akan tetapi, guru dapat mengembangkan materi mengajar dengan menghubungkan kearifan lokal kedalam materi pembelajaran (Sofiani \& Nurfadillah, 2020). Sehingga perkembangan pengetahuan mereka tidak hanya terbatas di teori saja. Tetapi pengetahuan perihal objek bersejarah juga sangat penting dalam menciptakan suasana belajar sejarah yang menyenangkan. Sumber belajar merupakan bagian penting dalam proses pembelajaran. Sumber belajar ini dapat berupa bahan, objek dan/atau rujukan yang dipakai dalam menunjang pembelajaran bisa dalam bentuk media elektronik dan cetak, narasumber, serta lingkungan fisik, alam, budaya, dan sosial. Dengan bantuan media ini guru akan mudah dalam mengajar serta menyesuaikan dengan kebutuhan peserta didik dan materi yang akan disampaikan (Buwono \& Dewantara, 2020).

Nilai-nilai kearifan lokal yang dihubungkan ke materi pembelajaran sejarah itu salah satunya yaitu melalui biografi Sultan Syarif Abdurrahman sebagai sumber belajar. Nilai-nilai kearifan local yang terkandung di dalam biografi Sultan Syarif Abdurrahman dapat mengingatkan kembali peran sentral Sultan Syarif Abdurrahman dalam mendirikan kota Pontianak yang kini menjadi ibukota Provinsi Kalimantan Barat. Mulai dari letaknya yang sangat strategis hingga perjalanan panjang yang dilalui Sultan Syarif Abdurrahman dalam menciptakan Pontianak sebagai salah satu kerajaan yang termasuk muda yang sangat disegani oleh kerajaan lain pada waktu itu. Kearifan lokal yang terkandung dalam biografi Sultan Syarif Abdurrahman dapat dijadikan materi dan sumber belajar bagi peserta didik. Korelasi diantara kearifan local dan pemebelajaran sejarah sangat berperan dalam membentuk karakter peserta didik dalam mengenal hal-hal yang ada di sekitar lingkungan peserta didik tinggal.

Disinilah pentingnya mendekatkan peserta didik secara aktif dengan kenyataan yang ada disekitar lingkungan hidup mereka. Kesadaran dapat tumbuh pada diri peserta didik dengan mengajak peserta didik merekonstruksi pengetahuannya sendiri terutama terhadap hal-hal yang dimilikinya. Sehingga peserta didik secara mandiri menggali pengetahuannya dan tidak merasa digurui. Dalam proses inilah guru menanamkan nilai-nilai pendidikan karakter kepada peserta didiknya, belajar atas kemauan diri sendiri bukan dipaksa oleh guru (Afiqoh et al., 2018). Pada aspek lain dengan mempelajari sejarah lokal biografi Sultan Syarif juga menjadi upaya guru mengajarkan nilai-nilai kearifan lokal kepada 
peserta didik yang turut menginternalisasi nilai nasionalisme. Hal ini tentu dilakukan untuk mencegah masuknya ideologi yang dapat menyebabkan mengkikis nasionalisme (Retnasari \& Hidayah, 2019). Hasil penelitian ini menunjukan bahwa dalam pembelajaran sejarah beberapa SMA di Kota Pontianak telah memanfaatkan biografi sultan Syarif Abdurrahman sebagai sumber belajar dalam pembelajaran sejarahnya. Namun pemanfaatan tersebut belum digunakan secara maksimal. Guru sejarah lebih sering terfokus pada materi pokok saja. Pemanafaatan biografi sultan Syarif Abdurrahman sebagai sumber pembelajaran sejarah sering dilakukan guru dalam mengembangkan materi pokok sejarah perkembangan Islam. Materi sejarah perkembangan islam ini terdapat pada kelas X di SMA. Dalam pemanfaatan biografi Sultan Syarif Abdurrahman Akadir sebagai sumber pembelajaran sejarah di sekolah yang dilakukan oleh guru dapat kita lihat dalam tiga aspek yakni perencanaan, pelaksanaan dan evaluasi.

\section{Perencanaan}

Perencanaan pembelajaran dikembangkan oleh guru dari silabus yang telah. Guru memasukan materi biografi Sultan Syarif Abdurrahman pada materi sejarah perkembangan Islam. Perencanaan ini dibuat guru dalam RPP atau Rencana Pelaksanaan Pembelajaran. Walapun sebagian tidak meyebutkan secara ekplisit tentang pengunaan biografi Sultan tersebut namun guru memasukan tentang sejarah perkembangan kota Pontianak yang dimula pada dan dipengaruhi oleh Kesultan Kadriah yang didirkan oleh Sultan Syarif Abdurrahman. Dari perencanaan guru ini dapat dilihat guru sudah menyiapkan pengembangan materi sejarah lokal terkait sultan Syarif Abdurrahman. Dalam perencanaan tersebut guru menyiapakan perencaanan wisata sejarah yang berkaitan dengan Sultan Syarif Abdurrahman.

\section{Pelaksanaan}

Perencanaan yang telah dibuat oleh guru tentu harus diimplementasikan dengan baik dalam pelaksanaan pembelajarannya. dalam perencanaan pemanfaatan biografi Sultan Syarif Abdurrahman Alkadri sebagai sumber pembelajaran yang telah diuraikan sebelumnya kemudian diimplementasikan dalam pembelajaran oleh guru. Pembelajaran tidak harus dilaksanakan di dalam kelas saja, namun bise di luar kelas. Wisata sejarah merupakan salah satu metode pembelajaran yang memanfaatkan lingkungan sekitar peserta didik yang dapat digunakan guru sejarah dalam megelola pembelajarannya. Memanfaatkan wisata Sejarah sebagai bentuk pembelajaran mengajak peserta didik untuk mengobservasi secara langsung warisan-warisan sejarah yang ada disekitarnya yang masih dapat dilihat sampai saat ini. Mengobservasi secara langsung warisan sejarah penting dilakukan karena peserta didik dapat mengenal dan memahami nilai-nilai kearifan lokalnya sehingga dapat 
diimplementasikannya untuk menata masa yang akan datang dengan lebih baik lagi sesuai dengan peren dan fungsi sejarah. Sejarah sebagai ingatan kolektif selalu memuat nilai-nilai pendidikan yang memiliki tujuan merekonstruksi kesadaran sejarah dan mengajarkan peserta didik untuk berpikir kritis dan sistematis (Suwarni \& Firmansyah, 2019). Pelaksanaan pembelajaranya dengan melakukan wisata sejarah, dengan mengunjungi tiga lokasi penting yang berkaitan dengan Sultan Syarif Abdurrahman yakni Masjid Jami' Sultan Syarif Abdurahaman, Istana Kesultanan Kadriah Pontianak dan Komplek Pemakaman Sultan di Batu Layang.

\section{Evaluasi}

Guru melakukan evaluasi terkait proses pembelajaran yang telah dilaksanakan dalam pemanfaatan Biografi Sultan Syarif Abdurrahaman. Evaluasi tersebut dilakukan dengan memberikan penugasan kepada peserta didik ketika melakukan wisata sejarah ketiga lokasi yang berkaitan dengan Sultan Syarif Abdurrahman berupa pembuatan makalah kelompok dari hasil observasi yang dilakukan oleh peserta didik. Hasil Makalah yang telah dibuat oleh peserta didik dipersentasikan didalam kelas dan guru memberikan penilaian dari 3 aspek yakni (a) Kualitas Makalah dengan tema Sultan Syarif Abdurrahman, (b) Kemampuan Peserta didik dalam mempersentasikan Hasil Makalahnya dan (c) Penguasaan Materi Biografi Sultan Syarif Abdurrahman Alkadrie.

\section{Kesimpulan}

Kesimpulan penelitian ini bahwa Sultan Syarif Abdurrahman Alkadrie merupakan pendiri kota Pontianak. Anak dari pernikahan antara Al-Habib Husin dengan Putri Nyai Tua. Al Habib Husain merupakan mufti atau pemangku adat Kerajaan Matan yang menikahi seorang dayang di Kerajaan Matan, Putri Nyai Tua. Perjalanan panjang telah digoreskan oleh Sultan Syarif Abdurrahman. Mulai dari pendirian kota Pontianak hingga perkembangan yang terjadi di kerajaan Pontianak pada masa pemerintahannya. Sultan yang sangat religius, bijaksana dan tegas pun tergambarkan dari cerita-cerita dalam buku-buku sejarah berdirinya kota Pontianak. Sehingga perlu dipelajari kembali perihal biografi Sultan Syari Abdurrahman sebagai motivasi peserta didik dalam berbuat dalam memberikan hal-hal baru di lingkungan sekitarnya. Memanfaatkan biografi Sultan Syarif Abdurrahman menjadi sumber belajar untuk memberikan variasi dalam pembelajaran sejarah. Sehingga dengan memanfaatkan biografi Sultan Syarif Abdurrahman dapat membuat peserta didik berpikir kritis perihal kesejarahan di ruang lingkupnya dan meningkatkan minat peserta didik dalam belajar sejarah. Dalam Pemanfaatan biografi Sultan Syarif ini dilaksankan dengan melakukan wisata sejarah ke tiga lokasi yang berkaitan dengan Sultan Syarif Abdurrahman yakni Masjid Jami', Istana Kadriah 
dan Komplek Pemakan Sultan Di Batu Layang. Dalam Implementasi Pemanfaatan tersebut dapat dilihat dari tiga Aspek yakni Perencanaan, Pelaksanaan dan Evaluasi.

Implikasi dari hasil penelitian ini akan menunjukan bahwa pengembangan materi sejarah lokal dapat digunakan oleh guru sejarah hampir pada setiap materi sejarah yang terdapat di kurikulum. Sehingga dalam hal ini guru dituntut untuk lebih kreatif dalam mengembangkan bahan ajar sejarah lokanya. Penggunaan Biografi Sultan Syarif Abdurrahman Alkadrie harus dimaksimalkan oleh guru sejarah, hal ini sangat penting karena dapat menjadikan pembelajaran menjadi lebih bermakna. Pimpinan sekolah sebagai pengambil kebijakan juga harus turut memberikan dukungan baik secara materil dan non materil sehingga penggunaan Biografi Sultan Syarif Abdurrahman Alkadrie dapat dilaksanakan dengan baik oleh guru. Perlu adanya penelitian selanjutnya terutama penelitian pengembangan model pembelajaran atau bahan ajar yang berisi penggunaan Biografi Sultan Syarif Abdurrahman Alkadrie, sehingga guru-guru sejarah dapat menggunakannya dalam proses pembelajaran sejarahnya.

\section{Daftar Pustaka}

Afiqoh, N., Atmaja, H. T., \& Saraswati, U. (2018). Penanaman Nilai Kearifan Lokal dalam Pembelajaran Sejarah Pokok Bahasan Perkembangan Islam di Indonesia Pada Siswa Kelas X IPS di SMA Negeri 1 Pamotan Tahun Ajaran 2017/2018. Indonesian Journal of History Education, 6(1), 42-53.

Amboro, K. (2015). Membangun Kesadaran Berawal Dari Pemahaman; Relasi Pemahaman Sejarah Dengan Kesadaran Sejarah Mahasiswa Program Studi Pendidikan Sejarah Fkip Universitas Muhammadiyah Metro. Historia, 3(2), 109. https://doi.org/10.24127/hj.v3i2.150

Andi, T. N. (2010). Pemerintahan Kota Pontianak Dari Sultan Sampai Walikota (Kumpulan Sejarah Kota Pontianak). Lentera Community.

Asma Dz, A. (2013). Pontianak Heritage dan Beberapa yang Berciri Khas. Literer Khatulistiwa.

Buwono, S., \& Dewantara, J. A. (2020). Analisis Konten Sumber Ajar IPS Pada SMP Di Kota $\begin{array}{llll}\text { Pontianak. Jurnal } & \text { Basicedu, }\end{array}$ https://doi.org/10.31004/basicedu.v4i3.432

Firmansyah, H. (2019). Heritage Kota Pontianak Sebagai Sumber. MASA: Journal of History, 1(2), 94-108. https://journal.ikippgriptk.ac.id/index.php/masa/article/view/1433

Firmanto, A. (2012). Jejak Sejarah Kesultanan Pontianak (Kajian Inskripsi Situs Makam Batu Layang) (pp. 249-278). Jurnal Lektur Keagamaan.

Hasanuddin. (2000). Sejarah Pemerintahan Potianak dari Masa ke Masa. Romeo Grafika.

Hasanuddin. (2014). Pontianak Masa Kolonial. Penerbit Ombak.

Hasanuddin. (2016). Politik Dan Perdagangan Kolonial Belanda Di Pontianak. Patanjala: Jurnal Penelitian Sejarah Dan Budaya, 8(2), 203. https://doi.org/10.30959/patanjala.v8i2.73

Hasbullah, M., \& Supriadi, D. (2012). Filsafat Sejarah. CV. Pustaka Setia. 
Hidayat, O. T., Muhibbin, A., Prasetiyo, W. H., Setyadi, Y. B., \& Dewantara, J. A. (2020). Global Citizen Preparation : Enhancing Early Childhood Education through Indonesian Local Wisdom. 8(10), 4545-4554. https://doi.org/10.13189/ujer.2020.081023

Kartodirdjo, S. (1993). Pendekatan Ilmu Sosial Dalam Metodologi Sejarah. PT Gramedia Pustaka Utama.

Kartodirjo, S. (2014). Pengantar Sejarah Indonesia Baru: 1500-1900 Dari Emporium Sampai Imperium. Penerbit Ombak.

Miles, M.B. \& Huberman, A. M. (1984). Qualitative data analysis: An expanded.

Pemerintah Provinsi Kalimantan Barat. (n.d.). Himpunan Naskah Sumber Arsip Kerajaan Kalimantan Barat. : Bidang Arsip Statis Bidang Perpustakaa, Kearsipan, dan Dokumentasi.

Poestaka, P. (1926). Panji Postaka 23 Februari 1926 tahun IV.

Pramayogi, I., Puji, R. P. N., \& Hartanto, W. (2019). INOVASI DALAM PEMBELAJARAN SEJARAH. Sindang; Jurnal Pendidikan Sejarah Dan Kajian Sejarah, 1(2), 17-22.

Purnaman, P. N. (2016). Mengembangkan Keterampilan Berpikir Kesejarahan Siswa Dalam Pembelajaran Sejarah Melalui Penggunaan Biografi Tokoh R.a Lasminingrat Sebagai Sumber Pembelajaran Sejarah. Jurnal Pendidikan Ilmu Sosial, 24(1). https://doi.org/10.17509/jpis.v24i1.1613

Retnasari, L., \& Hidayah, Y. (2019). Menumbuhkan Sikap Nasionalisme Warga Negara Muda di Era Globalisasi melalui Pendidikan Kewarganegaraan di Perguruan Tinggi (Studi pada Mahasiswa PGSD UAD). Jurnal Basicedu, 4(1), 79-88. https://doi.org/10.31004/basicedu.v4i1.303

Romadi, \& Kurniawan, G. F. (2017). PEMBELAJARAN SEJARAH LOKAL BERBASIS FOLKLORE UNTUK MENANAMKAN NILAI KEARIFAN LOKAL KEPADA SISWA. Sejarah Dan Budaya, 17(1), 79-94. http://journal2.um.ac.id/index.php/sejarah-danbudaya/article/view/1515

Sari, M. (2017). Peta Digital : Inovasi Pembelajaran Produktif Abad 21 dengan Smartphone dalam Pembelajaran Sejarah. In Prosiding Seminar Pendidikan Nasional Pemanfaatan Smartphone untuk Literasi Produktif Menjadi Guru Hebat dengan Smartphone. https://jurnal.fkip.uns.ac.id/index.php/psdtp/article/view/10987

Sayono, J. (2013). Pembelajaran Sejarah Di Sekolah: Dari Pragmatis Ke Idealis. Jurnal Sejarah Dan Budaya, 7(1), 9-17. http://journal.unnes.ac.id/sju/index.php/ijhe\%0APENGARUH

Sirnayatin, T. A. (2017). MEMBANGUN KARAKTER BANGSA MELALUI PEMBELAJARAN SEJARAH. Jurnal SAP, http://journal.lppmunindra.ac.id/index.php/SAP/article/view/1171

Sirrullah. (2019). Sejarah Kesultanan Kadriah Pontianak 1778-2017 M. http://digilib.uinsby.ac.id/29237/

Sofiani, Y., \& Nurfadillah, C. (2020). Nilai-Nilai Kearifan Lokal Dalam Biografi Bupati R.A.A. Kusumadiningrat (1839-1886) Sebagai Sumber Belajar Sejarah. HISTORIA: Jurnal Pendidik Dan Peneliti Sejarah, 3(2), 155-166. https://doi.org/https://doi.org/10.17509/historia.v3i2.24049.

Sulistyo, W. D. (2019). LEARNING ACTIVITIES FROM LEARNING RESOURCE: PEMANFAATAN DAN PEMAKNAAN SITUS SEJARAH KAWASAN ALUN-ALUN MERDEKA KOTA 
MALANG. In Jurnal Pendidikan Sejarah Indonesia (Vol. 2, Issue 1). https://doi.org/10.17977/UM0330V2I1P49-63

Sutopo, H. B. (2006). Metode Penelitian Kualitatif Dasar Teori dan Penerapanya Dalam Penelitian. UNS Press.

Suwarni, \& Firmansyah, H. (2019). ANALISIS WISATA SEJARAH DI KOTA KOLONIAL PONTIANAK. In MASA: Journal of History (Vol. 1, Issue 1). http://journal.ikippgriptk.ac.id/index.php/masa/article/view/1517

Veth, P. . (2012). Borneo Bagian Barat: Geografsi, Statistik, Historis Jilid 1, Terjemahan Borneo's wester-Afdeeling,Geographisch, Statistisch, Historisch voorafgegaan door eene algemeene schets des ganschen eilands a.b P.O.C.Yeri. Isntitut Dayakologi.

Willer, J. . (2015). Kronik Mempawah (dan Pontianak), dialihbahasakan oleh Pastor Yeri, OFMCap. Pohon Cahya. 